\title{
An Integrated Measurement Platform for a Solar Cell Based on Virtual Instruments
}

\author{
Zhen Wang $^{1, \mathrm{a}}$, Maokui Li ${ }^{1, \mathrm{~b}^{*}}$, Jian Zhang ${ }^{2, \mathrm{c}}$, Minglei Zhao ${ }^{1, \mathrm{~d}}$, Lu Luo ${ }^{1, \mathrm{e}}$ \\ ${ }^{1}$ School of Physics, Shandong University, Jinan, Shandong,250100,P.R. China \\ ${ }^{2}$ Department of Medical Engineering,General Hospital of Jinan Military Command \\ a wangzhen0822@gmail.com, ${ }^{b}$ limk@sdu.edu.cn, ${ }^{\mathrm{c}}$ gaoshansd@163.com, ${ }^{\mathrm{d}}$ Zhaoml@sdu.edu.cn, ${ }^{\mathrm{e}}$ luolu@mail.sdu.edu.cn \\ *Corresponding author: limk@sdu.edu.cn
}

\begin{abstract}
This paper presents an integrated measurement platform for a solar cell based on virtual instruments. A programmable high-speed digital input and output[I/O] device was adopted to control the stepper motor to allow for changes in the load resistance of the solar cell return circuit. Then, four programmable digital multimeters were used to acquire the voltage and current of the solar cell and sensors. We obtained the results by analyzing the experimental data. The measurement accuracy and efficiency were greatly improved in the virtual instrument platform compared with the conventional measurement method, which is of great significance for scientific research. Section I describes the problems with the conventional measurements of solar cell parameters and presents a solution to these problems using virtual instrument technology. Section II describ the hardware design of the measurement system. Section III describ the software design of the virtual instrument measurement system. Conventional measurement methods and the virtual instrument measurement method are compared in section IV.
\end{abstract}

Keywords-solar cell, virtual instruments, LabVIEW, DAQ

\section{INTRODUCTION}

Currently, the energy crisis is a serious problem worldwide. To solve this problem, many governments are developing photoelectric technology. One of the most pressing issues is establishing high-efficiency materials for photoelectric conversion.

The performance of a solar cell is characterized by a variety of parameters, such as the open-circuit voltage, short-circuit current, irradiance, temperature, maximum power voltage, maximum power current, maximum power, fill factor and conversion efficiency. To estimate the solar cell performance and thus further simulate, design, fabricate, and provide quality control of solar cells, an accurate knowledge of their parameters from experimental data is of vital importance[1].

Several methods for determining the parameters of solar cells have been proposed by several authors. Some of the methods involve the measurement of the illuminated I-V characteristics for a single level or different levels of illumination, while some methods use dark conditions, or dark and illumination measurements[3]. We chose to employ the illumination measurement in this study.

There are few instruments designed specifically for solar cell material measurements. To characterize a solar cell, it is necessary to measure some basic parameters using existing instruments and then perform many calculations, as, for example, in the measurement of the maximum power. We must manually adjust the load resistance, record the voltage and current via a traditional digital multimeter and then draw the curve of the voltage versus current.

Conventional testing methods for solar cell materials are relatively unadvanced and have some distinct disadvantages.[4]

1. They requires a significant amount of manual adjustment, the measurement accuracy is not high, and the methods are inefficient.

2. After measuring the basic parameters, many calculations must be performed to obtain the result required.These repetitive tasks waste time.

3. Because the temperature and irradiance are constantly changing, some parameters will change. The conventional measurement methods can only implement static measurements; dynamic measurements cannot be achieved.

To solve these problems, we propose the use of virtual instruments to perform these measurements. [4]

1. The load resistance can be automatically controlled to a high-precision. The computer program controls digital multimeters with a precision of six and a half, which improves the accuracy and measurement efficiency over the conventional testing methods.

2. A virtual instrument measurement system dynamically characterizes the solar cell parameters of the device under testing. Thus, dynamic measurements can be achieved.

3. Experiment data can be further processed by software to obtain the required values of solar cell parameters or curves. Software can generate or print reports automatically. It greatly improved the efficiency of data processing.

Solar cells have many parameters. Assuming that sufficient data sets have been obtained experimentally, the raw data must be converted into the local parameters of the solar cell[2]. We chose the measurement of the maximum power as an example. We must draw I-V curve and find the maximum product of the voltage and current.

\section{HARDWARE DESIGN}

To implement the maximum power measurement, we need a high-speed digital I/O device to control the stepper motor to allow for changes in the load resistance. The 
step-length of the load resistance can be controlled by the virtual instrument software. Then two programmable digital multimeters were used to acquire the voltage and current of the solar cell. These data can be used to calculate the maximum power. The connection of the hardware is shown in Fig. 1.

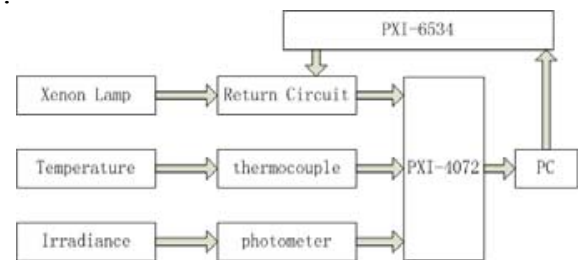

Fig.1. HARDWARE DESIGN OF THE VIRTUAL InSTRUMENT MEASUREMENT SYSTEM

\section{SOFTWARE DESIGN}

The software of the measurement system must generate the control signal, acquire data and analyze the experimental results. We choose NI PXI-6534 to generate the control signal and NI PXI-4072 to acquire the voltage and current $[5,6,7,8]$. The flowchart of the system is shown in Fig. 2.

1. The software must first be initialized, to set the system to a known state. We call this process system initialization.

2. NI PXI-6534 and NI PXI-4072 must be initialized.

3 . Some parameter configuration must be performed.

4. NI PXI-6534 outputs the control signal to change the load resistance of the solar cell's return circuit.

5. NI PXI-4072 acquires the voltage and current of the solar cell.

6. The acquired data are analyzed by the software.

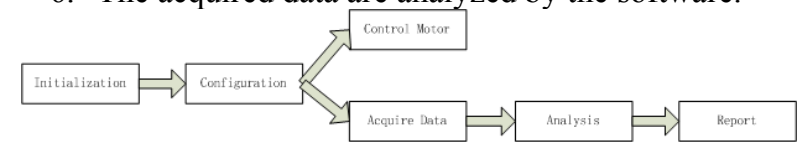

Fig.2. FLOWCHART OF THE SOFTWARE

A software screenshot is shown in Fig. 3. All of the measurement parameters can be set in this software interface, including, for example, the step-length of the load resistance. The curve of voltage and current can be plotted by analyzing the data acquired by NI PXI-4072. Then, we can obtain the parameters of the solar cell by analyzing the curve. The measurement can be stopped at any time by clicking the stop button. The experiment results can be printed or saved as html, Word, Excel files.

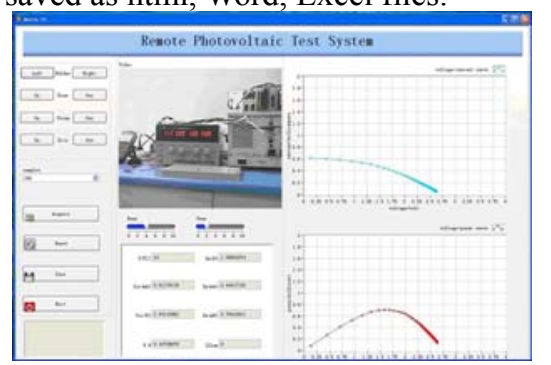

FIG.3. SCREENSHOT OF THE SYSTEM SOFTWARE

\section{EXPERIMENT RESULTS}

The experimental results of a solar cell measured by the conventional method and the new designed measurement platform are shown

in Table. 1.

TABLE. 1 EXPERIMENTAL RESULTS (THE SECOND ROW SHOWS RESULTS OBTAINED USING THE CONVENTIONAL METHOD, AND THE THIRD ROW SHOWS ReSUlts ObTAINED USING THE NEWLy DESIGNED MEASUREMENT PLATFORM)

\begin{tabular}{|c|c|c|c|c|}
\hline $\begin{array}{c}\text { short-circ } \\
\text { uit } \\
\text { current } \\
\text { A }\end{array}$ & $\begin{array}{c}\text { open-circ } \\
\text { uit } \\
\text { voltage } \\
\mathrm{V}\end{array}$ & $\begin{array}{c}\text { maximu } \\
\text { m power } \\
\text { current } \\
\mathrm{A}\end{array}$ & $\begin{array}{c}\text { maximu } \\
\text { m power } \\
\text { voltage } \\
\mathrm{V}\end{array}$ & $\begin{array}{c}\text { maximu } \\
\text { m power } \\
\mathrm{W}\end{array}$ \\
\hline 0.6116 & 2.6320 & 0.4439 & 1.5844 & 0.7033 \\
\hline 0.611791 & 2.631339 & 0.444171 & 1.585220 & 0.704109 \\
& & & & \\
\hline
\end{tabular}

\section{V.CONCLUSION}

The precision of the current and voltage in this method can reach $1 \mu \mathrm{A}$ and $1 \mu \mathrm{V}$, respectively. Compared with the traditional measurement method, this system improve the precision by a factor of several hundred. The measurement accuracy and efficiency were greatly improved using the virtual instrument platform compared with the conventional measurement method which is of great significance to the scientific research on solar cells.

\section{ACKNOWLEDGMENT}

This work was supported by the Independent Innovation Foundation of Shandong University, IIFSDU (No. 2012TS028), the National Nature Science Foundation of China (No. 51172129) and the Natural Science Foundation of Shandong Province (No. ZR2010EQ023).

\section{REFERENCES}

[1] Chunfu Zhang, Jincheng Zhang, Yue Hao, Zhenhua Lin, and Chunxiang Zhu: A simple and efficient solar cell parameter extraction method from a single current-voltage curve(JOURNAL OF APPLIED PHYSICS 110, 064504, 2011)

[2] J.Carstensen, G.Popkirov, J.Bahr, H.Foll: An advanced LBIC measurement technique for solar cell local characterization(Solar Energy Materials and Solar Cells; Volume 76, Issue 4, 1 April 2003, Pages 599-611)

[3] K.Bouzidi, M.Chegaar, A.Bouhemadou: Solar cells parameters evaluation considering the series and shunt resistance(Solar Energy Materials and Solar Cells; Volume 91, Issue 18, 6 November 2007, Pages 1647-1651)

[4] Zhang Xingcheng, Li Maokui, Liu Jianqiang, Fu Yunxu:An integrated measurement platform for piezoelectric transformer based on virtual instruments(Advanced Materials Research Vols. 301-303 (2011) pp 1507-1510)

[5] NI PXI-6534 specifications, National Instruments Corporation (2007)

[6] NI PXI-4072 specifications, National Instruments Corporation (2007)

[7] NI High-Speed Digitizers Getting Started Guide (2007)

[8] NI Digital Multimeters Getting Started Guide (2007) 